\title{
Experimental Study on Tensile Properties of GFRP Bars Embedded in Concrete Beams with Working Cracks
}

\author{
Li Dai ${ }^{1, a}$ and Xiongjun $\mathrm{He}^{1}$ \\ ${ }^{1}$ School of transportation, Wuhan University of Technology, 430063 Wuhan, China
}

\begin{abstract}
This paper presents the test results of an experimental study carried out to investigate the tensile properties of GFRP bars embedded in concrete beams with working cracks. The specimens were conditioned with sustained loading in $50^{\circ} \mathrm{C}$ alkaline solution and tap water for 6, 12, 18 months. The tensile test results show that the degradation rate of GFRP bars embedded in the concrete specimens with work cracks is larger than that of non-work cracks, while the effect of working cracks on the elastic modulus is not significant. The microstructure of GFRP bar surface before and after the test was observed by scanning electron microscopy (SEM), combined with Fourier-transform infrared spectroscopy (FTIR) and differential-scanning calorimetry (DSC), the degree of hydrolysis reaction and glass transition temperature is also analyzed. Compared with the hydrolysis of resin matrix, it can be found that the deterioration of glass fiber and the delamination at the interfacial is more pronounced for the GFRP bars embedded in concrete beams. As a result, the mainly reason that caused the degradation of GFRP bars embedded in concrete environments are the deterioration of glass fiber and the delamination at the interfacial.
\end{abstract}

\section{Introduction}

In recent decades, glass fibre reinforced polymer (GFRP) bars have been used in several concrete structures all over the world due to their several advantages such as corrosion resistance, light-weight, and high strength, and it has been promoted as a solution to the deterioration of bridges, buildings and other structures made with concrete reinforced with traditional materials, such as steel. As the application of GFRP bar used in civil engineering were more and more widely[1][2].

Numerous research studies have been conducted to investigate the tensile property of GFRP bars under simulate alkali solution environment [3][4]. Chen[5] conducted accelerated tests on GFRP bars in an alkaline solution at a high temperature $\left(60^{\circ} \mathrm{C}\right)$ for periods of 70 days. The tensile tests resulted in residual strength of $71.0 \%$ compared to the original tensile strength. Li[6]et al investigated the durability of GFRP bars exposed to harsh environment for 60 days, the environments was mixed with $\mathrm{Ca}(\mathrm{OH})_{2}, \mathrm{NaOH}$ and $\mathrm{KOH}$ solution to simulate the concrete pore solution. The results showed that the tensile strength losses $11.9 \%$ of the initial strength. Wang[7] also conducted an accelerated test on GFRP bars, the reduction in the tensile strength after 183 days in the alkaline solution at $40^{\circ} \mathrm{C}$ and $60{ }^{\circ} \mathrm{C}$ were $35.0 \%$ and $48.8 \%$, respectively.

\footnotetext{
${ }^{\mathrm{a}}$ Corresponding author : dlwhut2012@163.com
} 
Thus, based on the above review, it can be found that there has achieved an abundant results. However, these studies were all focused on evaluating tensile strength of GFRP bars under artificial simulated concrete pore solution, which is different from the actual concrete alkaline environmental condition. Besides, some scholars pointed out that the traditional accelerated aging in alkaline solution is too severe and prematurely degrades the GFRP bars [8-12]. The paper presents the actual concrete environment influence on tensile properties of GFRP bars.

\section{Experimental program}

\subsection{Test specimens}

\subsubsection{Raw materials}

The GFRP bar used in the study was composed of $72 \%$ glass fiber and $28 \%$ vinyl ester resin, and manufactured using a pultrusion process by Nanjing Feng Hui Composite Materials Co., LTD., China. The surface of the GFRP bar was ribbed with a nylon laminate during the pultrusion. The mechanical and physical properties of $10 \mathrm{~mm}$ diameter GFRP bars, as provided by the manufacturer, are summarized in Table 1. The bar's circular cross section is manufactured by a process that couples pultrusion with sand coating along the external surface of the bar.

Table 1. Mechanical properties of the GFRP bar

\begin{tabular}{|c|c|c|c|}
\hline $\begin{array}{c}\text { Diameter } \\
(\mathbf{m m})\end{array}$ & $\begin{array}{c}\text { Ultimate } \\
\text { tension }(\mathbf{k N})\end{array}$ & $\begin{array}{c}\text { Tensile } \\
\text { strength }(\mathbf{M P a})\end{array}$ & $\begin{array}{c}\text { Elastic } \\
\text { Modulus (GPa) }\end{array}$ \\
\hline 10 & 96 & 1223 & 51 \\
\hline
\end{tabular}

\subsubsection{Test specimens}

In order to investigate the tensile properties of GFRP bars embedded in actual concrete beams, the concrete specimens were rectangular plain concrete beams with a length of $1100 \mathrm{~mm}$, width of $80 \mathrm{~mm}$, and depth of $110 \mathrm{~mm}$ (as shown in Fig. 1), with a single longitudinal GFRP reinforcement bar centered at $30 \mathrm{~mm}$ from the bottom of the section, and no shear reinforcement was used in the beams. Concrete beams were cast according to code for design of concrete structures (GB50010-2010), with 28 days target strength of $30 \mathrm{MPa}$. The beams were cast together with 3 concrete cubes used to determine the mechanical properties of the concrete. The concrete used for casting the beams was provided by a local ready-mix supplier with a maximum aggregate size of $10 \mathrm{~mm}$, and the water cement ratio is 0.4 .

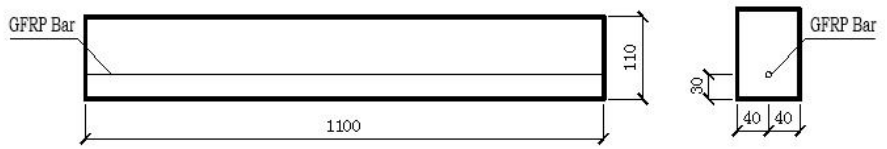

Figure 1. Geometry size of concrete beam

\subsection{Test plan and environmental conditions}

A spring-bracket assembly was fabricated by the research team to apply the sustained flexural loading and to produce a stable crack[13], the assembly consisted of steel frames, long threaded bolts with nuts and steel springs with a spring coefficient is $40 \mathrm{~N} / \mathrm{mm}$. The sketch illustrating of the sustained loading setup is shown in Fig. 2. 


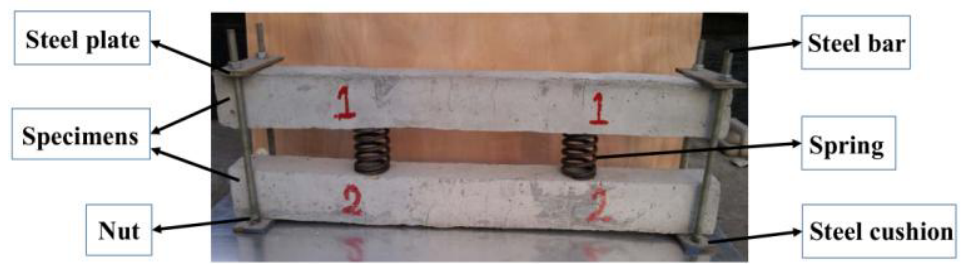

Figure 2. View of load setup

The beams were placed back to back, the inner two load points were located $200 \mathrm{~mm}$ from the outer load points, while the two outer load points were located $100 \mathrm{~mm}$ inward from the ends of the beam, Preliminary four-point flexure tests were performed to determine the ultimate bending moment of the beams and provide the original design data for pre-cracked load. Flexural cracks were introduced in the beams by subjecting them to the pre-cracked load. Failure of four-point flexure tests occurred in the shear/compression mode at one of the inner load points at a mean applied moment of $0.8 \mathrm{kN} \cdot \mathrm{m}$. Beams were pre-cracked at a bending moment of $0.39 \mathrm{kN} \cdot \mathrm{m}$. A pair of beams was not precracked as a reference, and the rest of beams were pre-cracked by four-point flexure tests after a specified time.

To simulate the working state under the sustained loading, sustained four point flexural loads corresponding to $25 \%$ of the measured ultimate strength of GFRP bars were applied by spring-bracket assembly. The sustained load should be avoid concrete continuous beam of creep rupture. The steel spiral springs were periodically monitored to make the cross section bending moment within the given range of error.

In order to make a contrast analysis on the tensile properties of GFRP bars embedded in conrete beams with working cracks under different enviroments, specimens were subjected to three environmental conditions for 6,12 and 18 months. The enviromental conditions were divided into three main types as follows: (1) specimens exposed to indoor natural environment as reference samples; (2) accelerated aging of specimens aged in $50{ }^{\circ} \mathrm{C}$ alkaline solution with $\mathrm{pH}$ value of 12.7 ; (3) accelerated aging of specimens aged in $50{ }^{\circ} \mathrm{C}$ tap water to simulate high humidity environment of application. The test program is summarised in Table 2.

Table 2. Test program

\begin{tabular}{|c|c|c|c|c|c|c|c|}
\hline \multirow[t]{2}{*}{ Environment } & \multirow[t]{2}{*}{ Work cracks } & \multirow[t]{2}{*}{ Load level } & \multirow[t]{2}{*}{ Name } & \multirow{2}{*}{$\begin{array}{c}\text { Temperature } \\
\left({ }^{\circ} \mathrm{C}\right)\end{array}$} & \multicolumn{3}{|c|}{$\begin{array}{l}\text { Exposure time } \\
\text { (month) }\end{array}$} \\
\hline & & & & & 6 & 12 & 18 \\
\hline Controlled & Non pre-crack & 0 & $\mathrm{RE}$ & - & - & - & - \\
\hline \multirow{2}{*}{$\begin{array}{l}\text { Alkaline } \\
\text { solution }\end{array}$} & Pre-crack & $25 \%$ & APS25 & \multirow{2}{*}{50} & 4 & 4 & 4 \\
\hline & Non pre-crack & 0 & AS0 & & 4 & 4 & 4 \\
\hline \multirow{2}{*}{ Tap water } & Pre-crack & $25 \%$ & TPW25 & \multirow{2}{*}{50} & 4 & 4 & 4 \\
\hline & Non pre-crack & 0 & TW0 & & 4 & 4 & 4 \\
\hline
\end{tabular}

\subsection{Test instruments}

After the end of each accelerated exposed period, the beams were unloaded and the GFRP embedded bars in the tested beams were carefully extracted for tensile tests. The overall length of each bar was 
$1100 \mathrm{~mm}$. To prevent shear failure on both ends of the GFRP bar, a $250 \mathrm{~mm}$ long steel pipe anchorage was fixed on the GFRP bar ends. The tensile tests were conducted in a SHT4106-G type microcomputer controlled electro-hydraulic servo universal testing machine according to the relevant requirements of ACI440.3R-04 B2. The applied load for each bar was recorded during the test with a data acquisition system monitored by a computer. In addition, scanning electron microscopy (SEM) and differential scanning calorimetry (DSC) were performed to observe and analyse the possible degradation of glass fibres and polymer matrix.

\section{Results and discussion}

\subsection{Tensile property}

The results of the tensile tests on the GFRP Bar showed an approximately linear behaviour with brittle failure. Specimen failed through the rupture of fibres, the failure was accompanied by delamination of fibres and resin. A similar failure mode was observed for GFRP bars embedded in concrete specimen.

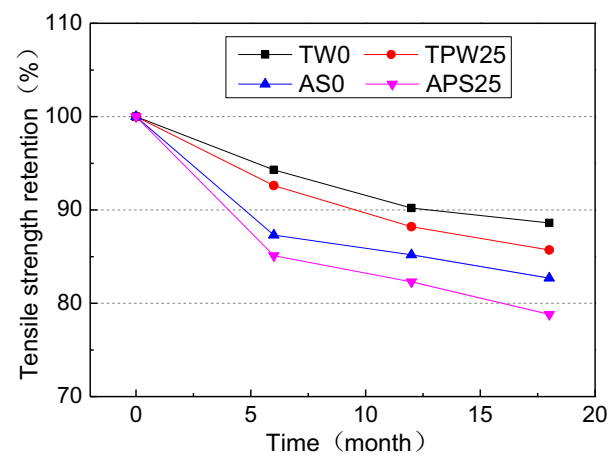

(a) tensile strength

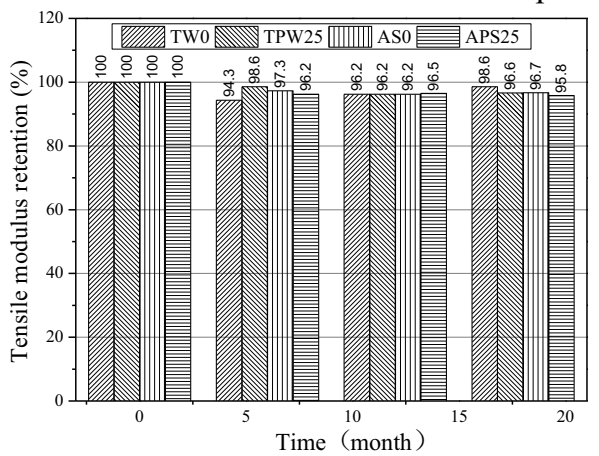

(b) tensile modulus

Figure 3. Change of tensile property of GFRP bars under different environments

In order to compare the tensile strength before and after accelerate aging test, the paper take the retention ratio as evaluation index. Figs. 3 show the tensile strength retention and tensile modulus retention, respectively. It can be seen from the Fig. 3(a) that the influence on the tensile strength of GFRP exposed in alkaline solution was significant greater than that of exposed in tap water. For the APS25 specimens, the tensile strength retention were decreased by $7.5 \%, 5.9 \%$ and $6.8 \%$ respectively after 6, 12 and 18 months of exposure than TPW25 specimen. It can be explained that the OHaccelerated the degradation rate of GFRP bar.

After 6, 12 and 18 months of exposure, the tensile modulus of AS0 specimen loss was $2.7 \%, 3.8 \%$ and $3.3 \%$ respectively. Compared with AS0 specimen, the modulus loss slightly increased to 1.1, $0.3 \%$ and $0.9 \%$, respectively. For all environments, a slight decrease ranging between $0 \%$ and $6 \%$ was observed. These results are in good agreement with the experiments conducted by different researchers.

\subsection{Microstructural analysis}




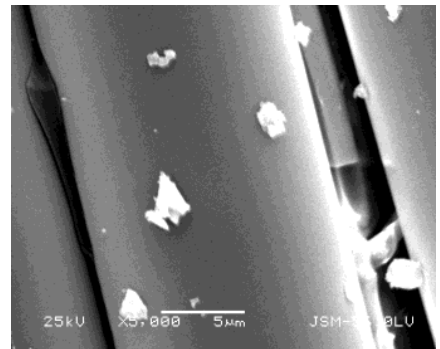

(a) RE $(\times 5000)$

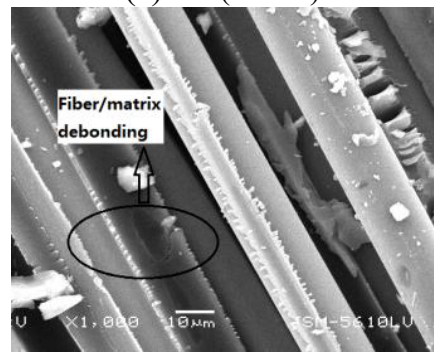

(d) TPW25-18 months $(\times 1000)$

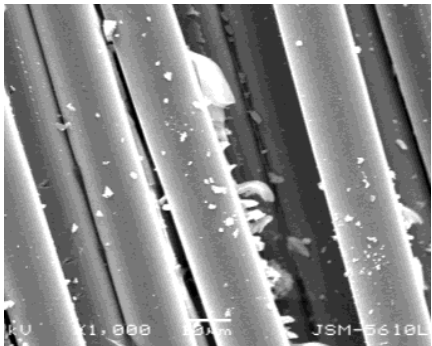

(b) RE $(\times 1000)$

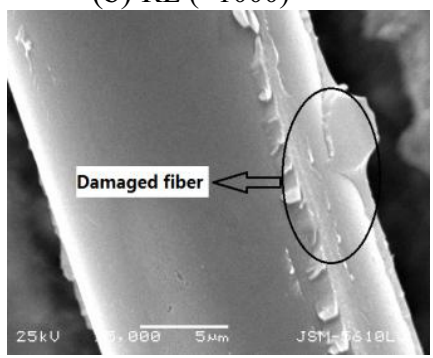

(e) AS0-18 months $(\times 5000)$

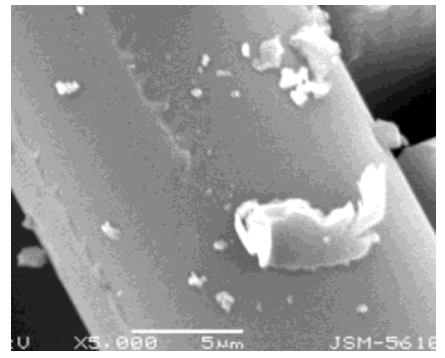

(c) TW0-18 months $(\times 5000)$

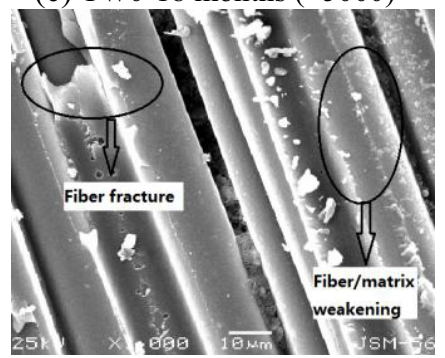

(f) APS25-18 months $(\times 1000)$

Figure 4. Micrographs of the GFRP bars

The microstructure of GFRP bars before and after the aging tests can be clearly observed by SEM images. As shown in Fig.4 (a) and 4(b), there was almost no deterioration in the glass fibres, while the matrix around the fibre in both the TW0 and AS0 specimen were seriously affected by the environment. No damage occurred in the GFRP bars that embedded in concrete without work cracks and sustained load (Fig.4 (c) and 4(e)). However, with the increase of sustained load, part of the fibre fracture and the delamination at the interface of fibre and matrix in both TPW25 and APS25 (Fig.4 (d) and 4(f)) specimen. It is worth mentioning that debonding at the interface are the most common phenomena occurring in a GFRP material under sustained load in adverse environment.

\subsection{Differential Scanning Calorimetry}

Table 3. The glass transition temperature of GFRP bar

\begin{tabular}{|c|c|c|c|c|c|}
\hline Conditioning & $\begin{array}{c}\text { Temperature } \\
\left({ }^{\circ} \mathrm{C}\right)\end{array}$ & $\begin{array}{c}\text { Duration } \\
(\mathrm{m})\end{array}$ & $\begin{array}{c}\mathrm{T}_{\mathrm{g}} \text { run } 1 \\
\left({ }^{\circ} \mathrm{C}\right)\end{array}$ & $\begin{array}{c}\mathrm{T}_{\mathrm{g}} \text { run } 2 \\
\left({ }^{\circ} \mathrm{C}\right)\end{array}$ & $\begin{array}{c}\text { Cure ratio } \\
(\%)\end{array}$ \\
\hline Controlled & - & - & 124 & 126 & 98.4 \\
\hline TPW25 & 50 & 18 & 120 & 124 & 96.8 \\
\hline APS25 & 50 & 18 & 118 & 123 & 96.0 \\
\hline
\end{tabular}

Table. 3 presents the Glass transition temperature $\left(\mathrm{T}_{\mathrm{g}}\right)$ for the first and second heating scans of the controlled TPW25, and APS25 samples. It is noticed that for all tested samples, the $\mathrm{T}_{\mathrm{g}}$ values corresponding to the second heating run are higher than that of the first. This shift indicates that the samples had not been fully cured. The results in Table 3 also show no significant changes in $\mathrm{T}_{\mathrm{g}}$ values for the specimens APS25. This indicates that DSC analysis detected no major impact effect on the resin's thermal properties as the result of the conditioning.

\section{Conclusions}

Based on the results of this study, the following conclusions can be drawn:

(1) When the specimen exposed in the same corrosive solution, the degradation rate of GFRP bar embedded in specimen with working cracks was faster than that of without cracks. While the work 
cracks has no significant influence on the tensile elastic of the GFRP bar, the degradation rate of elastic modulus was no more than $5 \%$ in the whole test process.

(2) The micro-cracks in the concrete increased the effect of the external corrosion environment on the durability properties of the GFRP bar, but it cannot change the mechanisms of the mechanical degradation of the GFRP bar. No changes of the $T_{g}$ occur as observed by differential scanning calorimetry.

(3) Compared with the deterioration of resin matrix, the deterioration of glass fibre and the delamination at the interface is more pronounced for GFRP bar embedded in concrete environments.

\section{Acknowledgments}

This work is financially supported by the National Nature Science Foundation of China with Grant No. 51178361. The authors wish to gratefully thank the Material Research and Testing Center of Wuhan University of Technology for their assistance.

\section{References}

1. A. Yousef., EI-gamal Sheriff, H.A Tarek, et al. Effect of harsh environmental conditions on the tensile properties of GFRP bars. Composite. Part B: Engineering, (2013), 45(1): 835-844.

2. A. Mufti, N. Banthia, B. Benmokrane, et al. Durability of GFRP composite rods. Concr Inter, (2007), 29(2):37-42.

3. F. Micelli, A. Nanni. Durability of FRP rods for Concrete Structures. Constr Build Mater. (2004), 18(7):491-503.

4. A. Mukherjee, S.J Arwikar, Performance of glass fiber reinforced polymer reinforcing bars in tropical environments part I: Structural scale tests. ACI Structural J, (2005), 102(5): 745-753.

5. Y. Chen, J.F. Davalos, I. Ray, and H Y Kim. Accelerated aging tests for evaluations of durability performance of FRP reinforcing bars for concrete structures. Compos Struct. (2007), 78(1), 101111.

6. C.C Li, A.M Yu, Y.L Wang. Durability of FRP rebars in alkaline environment of concrete. Build Sci, (2013), 29(1), 47-51. (in Chinese)

7. W. Wang, W.C Xue. Accelerated aging tests for evaluations of tensile properties of GFRP bars exposed to alkaline solution. J Build Mater, (2012), 15(6):760-766.

8. M. Robert, P. Cousin, B. Benmokrane. Durability of GFRP reinforcing bars embedded in moist concrete. J Compos Constr, (2009), 13(2): 66-73.

9. C. Sun, W.H Qiu, X.B Zeng. Experimental research on long-term mechanical behavior of GFRP bars in different environmental conditions. FRP/CM. (2014), 8:88-91.

10. A. Debaiky, G. Nkurunziza, B. Benmokrane, et al. Residual tensile properties of GFRP reinforcing bars after loading in severe environments. J Compos Constr, (2006), 10:370-380.

11. M. Robert, B. Benmokrane. Combined Effects of Saline Solution and Moist Concrete on Longterm Durability of GFRP Reinforcing Bars. Constr Build Mater, (2013), 38, 274-284.

12. G.Wu, Y. Zhu, Z.Q Dong et al. Experimental study on the corrosion resistance performance of BFRP bars in the alkaline environment. China Civil Engine J. (2014), 47(8):32-41.

13. L. Dai, X.J He, W.R Yang. Experimental study on the durability of GFRP bars embedded in actual concrete environment. FRP/CM. (2015), 8:75-79. 